\title{
Inhibitory role of AMP-activated protein kinase in necroptosis of HCT116 colon cancer cells with p53 null mutation under nutrient starvation
}

\author{
DAN-DIEM THI LE*, SAMIL JUNG ${ }^{*}$, NGUYEN THI NGOC QUYNH, ZOLZAYA SANDAG, \\ BEOM SUK LEE, SUBEEN KIM, HYEGYEONG LEE, HYOJEONG LEE and MYEONG-SOK LEE \\ Department of Biological Science, Sookmyung Women's University, Seoul 04310, Republic of Korea
}

Received May 30, 2018; Accepted October 12, 2018

DOI: $10.3892 /$ ijo.2018.4634

\begin{abstract}
Simultaneous induction of other types of programmed cell death, alongside apoptosis, in cancer cells may be considered an attractive strategy for the development of more effective anticancer therapies. The present study aimed to investigate the role of AMP-activated protein kinase (AMPK) in nutrient/serum starvation-induced necroptosis, which is a programmed form of necrosis, in the presence or absence of p53. The present study detected higher cell proliferation and lower cell death rates in the HCT116 human colon cancer cell line containing a p53 null mutation (HCT116 $\mathrm{p} 53^{-/}$) compared with in HCT116 cells harboring wild-type p53 (HCT116 p53 $3^{+/+}$), as determined using a cell viability assay. Notably, western blot analysis revealed a relatively lower level of necroptosis in HCT116 $\mathrm{p} 53^{-/-}$cells compared with in HCT116 $\mathrm{p} 53^{+/+}$cells. Investigating the mechanism, it was revealed that necroptosis may be induced in HCT116 $\mathrm{p} 53^{+++}$cells by significantly increasing reactive oxygen species (ROS) and decreasing mitochondrial membrane potential (MMP), whereas little alterations were detected in $\mathrm{HCT} 116 \mathrm{p} 53^{-/}$cells. Unexpectedly, a much lower level of ATP was detected in HCT116 $\mathrm{p} 53^{-/}$cells compared with in HCT116 p53 $3^{++}$cells. Accordingly, AMPK phosphorylation on the Thr172 residue was markedly increased
\end{abstract}

Correspondence to: Professor Myeong-Sok Lee, Department of Biological Science, Sookmyung Women's University, 100 Cheongpa-ro 47-gil, Yongsan-gu, Seoul 04310, Republic of Korea

E-mail: mslee@sookmyung.ac.kr

${ }^{*}$ Contributed equally

Abbreviations: PCD, programmed cell death; MMP, mitochondrial membrane potential; ROS, reactive oxygen species; AMPK, AMP-activated protein kinase; DCFH-DA, 2',7'-dichlorodihydrofluorescein diacetate; DM, dorsomorphin dihydrochloride; AICAR, 5-aminoimidazole-4-carboxamide ribonucleotide

Key words: necroptosis, p53, AMP-activated protein kinase in HCT116 $553^{-/}$cells. Furthermore, western blot analysis and ROS measurements indicated that AMPK inhibition, using dorsomorphin dihydrochloride, accelerated necroptosis by increasing ROS generation in HCT116 p $53^{-/-}$cells. However, AMPK activation by AICAR did not suppress necroptosis

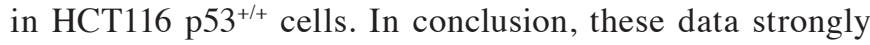
suggested that AMPK activation may be enhanced in HCT116 $\mathrm{p} 53^{-/}$cells under serum-depleted conditions via a drop in cellular ATP levels. In addition, activated AMPK may be at least partially responsible for the inhibition of necroptosis in HCT116 p53 $^{-/-}$cells, but not in HCT116 p53 $3^{+/+}$cells.

\section{Introduction}

In recent decades, apoptosis has been targeted as a therapeutic strategy to induce cancer cell death; therefore, several currently available anticancer drugs are designed to activate the apoptotic pathway directly or indirectly. However, numerous cancer cell types have acquired resistance to apoptosis by altering apoptosis-associated signaling pathways (e.g., loss of caspase 3), which has been a major obstacle to traditional chemotherapy. Therefore, other types of programmed cell death (PCD) have been explored. Dysregulation of PCD may induce various diseases, including numerous types of cancer. Initially, cell death has traditionally been divided into two types: Regulated cell death, i.e., apoptosis, and unregulated and accidental cell death, i.e., necrosis. However, more recent work has led to further information regarding the concept of cell death. One conceptual alteration is that another type of necrosis has been identified, which is considered to be a type of PCD; this type of necrosis has been named necroptosis (1-4). Therefore, it has been accepted that two types of necrosis exist, unregulated necrosis and regulated necroptosis. The present study focused on targeting necroptosis as an alternative strategy for treating cancer.

Necroptosis is a caspase-independent form of cell death, which is morphologically characterized by a loss of physical integrity, including swelling of organelles, increase in cellular volume, disruption of plasma and mitochondrial membranes, and release of intracellular contents. The most well studied signaling pathway for the induction of necroptosis is tumor necrosis factor-mediated 
necroptosis, which is mainly mediated by activation of three core regulators: Receptor-interacting serine/threonine protein kinase (RIP)1, RIP3 and mixed lineage kinase domain-like protein (MLKL) (1,5-9). These regulators form three complexes (membrane-bound complex I, complex II and necrosome) sequentially, by changing binding partners $(1,5-7,10)$. Necroptosis can be induced by various types of stress, including extreme nutrient deficiency. Unlike normal cells, cancer cells require unusually large amounts of nutrients to support their uncontrolled growth and proliferation; therefore, they are more easily exposed to severe nutrient deficiencies compared with normal cells. However, many cancer cells develop tolerance and overcome nutrient limitations by increasing nutrient uptake through alterations in metabolic signaling pathways or by activating angiogenesis (11-16). Therefore, it is important to elucidate these mechanisms, in order to develop novel therapeutic approaches. Therefore, this study initially focused on p53 and AMP-activated protein kinase (AMPK), as they are well known to serve various important roles under nutrient-deprived conditions and are considered promising therapeutic targets for cancer treatment.

One of the most powerful tumor suppressors, p53, is considered an appealing target for effective cancer therapy. Notably, approximately half of human cancers are known to have defective p53 expression, and p53 has been reported to be involved in several types of cell death [e.g., apoptosis, caspase-independent apoptosis (CIA), autophagy-mediated cell death, necroptosis, entosis, anoikis, paraptosis, pyroptosis, ferroptosis, mitotic catastrophe and efferocytosis] (17). It is widely accepted that p53 sensitizes normal cells to stressful conditions, including nutrient starvation. Mutations or deletions of p53 in cancer cells may overcome cell death pathways; therefore, these cells may exhibit resistance to chemotherapeutic drugs. Considering its vital roles in the regulation of cell death in response to various stressors, determining the role of p53 in the regulation of necroptosis may present a novel therapeutic strategy for cancer treatment.

AMPK also serves several vital roles in the regulation of metabolism and energy homeostasis. Cellular stress, such as nutrient starvation, induces the activation of AMPK, which is important for restoring intracellular energy balance. Activated AMPK inhibits energy-consuming biosynthetic processes and activates ATP biosynthesis (18). The most well known function of AMPK is its involvement in autophagy, in which it directly or indirectly promotes autophagy. In normal cells, AMPK acts as a metabolic tumor suppressor protein by activating autophagy to remove damaged or unnecessary proteins and organelles (19-25). However, it also functions as an oncogenic protein by protecting cancer cells from cell death by supporting their uncontrolled growth and proliferation $(22,26,27)$. In contrast to its well-known function in autophagy, few studies have reported on its role in necroptosis.

The present study aimed to determine how cancer cells evade necroptosis under nutrient starvation, and revealed that enhanced AMPK activation may suppress necroptosis in p53-null cells ( $553^{-/-}$) but not in wild type cells ( $\left.153^{+/+}\right)$under the same conditions.

\section{Materials and methods}

Cell lines, cell culture and cell treatment. The colorectal carcinoma cell lines, HCT116 p53 ${ }^{+/+}$and HCT116 p53/-, were a gift from Dr B. Vogelstein (Johns Hopkins University, Baltimore, MD, USA) (28). The cells were cultured in Roswell Park Memorial Institute (RPMI)-1640 medium (WelGENE, Inc., Gyeongsan, South Korea) supplemented with $10 \%$ fetal bovine serum (FBS; Gibco; Thermo Fisher Scientific, Inc., Waltham, MA, USA) and 1\% Antibiotic-Antimycotic solution (cat. no. 15240-06; Gibco; Thermo Fisher Scientific, Inc.). Both cell lines were grown at $37^{\circ} \mathrm{C}$ in a humidified atmosphere containing $5 \% \mathrm{CO}_{2}$ and $95 \%$ air. Dorsomorphin dihydrochloride (DM; cat. no. sc-361173; Santa Cruz Biotechnology, Inc., Dallas, TX, USA) and 5-aminoimidazole-4-carboxamide ribonucleotide (AICAR; cat. no. BML-EI330; Enzo Life Sciences, Inc., Farmingdale, NY, USA) were used to inhibit and activate AMPK, respectively. Cells were treated with 0,5 and $10 \mu \mathrm{M}$ DM for $48 \mathrm{~h}$, or with $0,75,150$ and $300 \mu \mathrm{M}$ AICAR for $48 \mathrm{~h}$ at $37^{\circ} \mathrm{C}$.

Cell viability and proliferation analysis. Cell viability was analyzed using the Cell Viability, Proliferation \& Cytotoxicity Assay kit (EZ-CYTOX, cat. no. EZ-3000; DoGenBio, Seoul, South Korea), according to the manufacturer's protocol, in three replicates. Briefly, HCT116 p53 $3^{++}$and HCT116 p53 ${ }^{-/}$cells $\left(\sim 2 \times 10^{4}\right.$ cells/well) were seeded in 96-well plates for $24 \mathrm{~h}$, and the media were replaced with RPMI 1640 media with or without $10 \%$ FBS for 24,48 , or $72 \mathrm{~h}$. Cell viability was evaluated by measuring absorbance at $450 \mathrm{~nm}$ using a Gemini XPA Microplate Reader. Cell proliferation was analyzed by Trypan blue (EBT-001; NanoEnTek, Inc., Seoul, South Korea) staining under the same conditions; $10 \mu \mathrm{l}$ cells $\left(\sim 10^{5}\right.$ cells $)$ and $10 \mu 1$ Trypan blue were mixed in $1.5 \mathrm{ml}$ microcentrifuge tubes at room temperature and were then placed into an $\mathrm{EVE}^{\mathrm{TM}}$ cell counting slide (NanoEnTek, Inc.), in order to count the number of live or dead cells. Cell proliferation was determined by counting the number of live cells at various time points $(0,24,48$ and $72 \mathrm{~h})$ after culturing in complete media (CM) or serum-starved media (SS). Morphological images of cells were captured using an optical microscope with IS capture software (KI-400F; Korea Lab Tech, Seongnam, South Korea) at X100 magnification.

Analysis of necroptosis, apoptosis and autophagy. Necroptosis, apoptosis and autophagy were detected using western blotting for the detection of the following corresponding biomarkers: Cyclophilin (Cyp)A and high mobility group box 1 (HMGB1) for necroptosis (29); cleaved poly (ADP-ribose) polymerase (PARP) for apoptosis; and p62/sequestome 1 (SQSTM1) and microtubule-associated protein 1A/1B-light chain 3 (LC3) for autophagy. Necroptosis was also analyzed using the Green Fluorescent Protein-Certified Apoptosis/Necrosis Detection kit (cat. no. ENZ-51002; Enzo Life Sciences, Inc.), according to the manufacturer's protocol. This kit contained 7-aminoactinomycin D (7-AAD) and Annexin V, which were used to detect necroptosis and apoptosis, respectively.

Western blotting. HCT116 p53 $3^{+/+}$and HCT116 p53 cells $(\sim 5 \times 106 / \mathrm{ml})$ were centrifuged, (Smart R17; Hanil Scientific, 
Inc., Gimpo, South Korea) at $3,000 \times \mathrm{g}$ for $3 \mathrm{~min}$ at $4^{\circ} \mathrm{C}$, washed in ice-cold PBS and lysed in radioimmunoprecipitation assay (RIPA) lysis buffer (50 mM Tris, $\mathrm{pH} 7.5 ; 48 \mathrm{mM}$ $\mathrm{NaCl} ; 1 \%$ Triton X-100 and $1 \mathrm{mM}$ EGTA) with $0.5 \mathrm{mM}$ $\mathrm{Na}_{3} \mathrm{VO}_{4}, 1 \mathrm{mM}$ DTT and $1 \mu \mathrm{l}$ premade protease inhibitor cocktail III (cat. no. P-1512; AG Scientific, Inc., San Diego, CA, USA)/ml RIPA solution. Protein concentration was quantified using a protein assay kit (Bio-Rad Laboratories, Inc., Hercules, CA, USA), and 10 or $30 \mu \mathrm{g}$ protein was loaded into each lane. Subsequently, proteins were separated by 10 or $12 \%$ SDS-PAGE and were then transferred onto an Immobilon- $\mathrm{P}^{\circledR}$ polyvinylidene fluoride transfer membrane (cat. no. IPVH00010; EMD Millipore, Billerica, MA, USA). Membranes were then blocked using 5\% skimmed milk in PBS for $30-60 \mathrm{~min}$ at $20-25^{\circ} \mathrm{C}$, and incubated overnight at $4^{\circ} \mathrm{C}$ with the primary antibodies. After washing with Tris-buffered saline containing 1\% Tween-20 (cat. no. T1027; Biosesang, Seongnam, Korea), membranes were incubated with the corresponding secondary antibodies: Anti-rabbit (cat. no. 7074S, 1:5,000; Cell Signaling Technology, Inc., Danvers, MA, USA), anti-mouse (cat. no. sc-516102, 1:5,000; Santa Cruz Biotechnology, Inc.) and anti-goat (cat. no. sc-2020, 1:5,000; Santa Cruz Biotechnology, Inc.). Immunodetection was performed using the PowerOpti-ECL western blotting detection reagent (cat. no. LR01-02; BioNote, Inc., Hwaseong, South Korea). The antibodies used in this study were as follows: Mouse monoclonal anti-p53 (cat. no. sc-126, 1:10,000; Santa Cruz Biotechnology, Inc.), rabbit monoclonal anti-AMPK $\alpha$ (cat. no. 2603P, 1:3,000) and anti-phosphorylated (p)-AMPK $\alpha$ (Thr172) (cat. no. 2535S, 1:3,000) (both Cell Signaling Technology, Inc.), rabbit polyclonal anti-CypA (cat. no. BML-SA296, 1:3,000), rabbit anti-HMGB1 (1:3,000, cat. no. ALX-210-964) (both Enzo Life Sciences, Inc.), rabbit polyclonal anti-PARP (cat. no. 9542S, 1:3,000), rabbit polyclonal anti-p62/SQSTM1 (cat. no. 5114, 1:3,000) (both Cell Signaling Technology, Inc.), mouse monoclonal anti-LC3 (cat. no. ALX-803-082, 1:2,500; Enzo Life Sciences, Inc.) and mouse monoclonal anti- $\beta$-actin (cat. no. sc-47778, 1:5,000; Santa Cruz Biotechnology, Inc.). $\beta$-actin was used as a loading control. To measure the extracellular levels of necroptosis biomarkers (CypA and HMGB1), $80 \mu 1$ media were collected from $10 \mathrm{ml}$ cell culture media and mixed with $20 \mu \mathrm{l}$ 5X SDS-PAGE loading buffer (cat. no. S2002; Biosesang), of which $20 \mu 1$ was separated by $12 \%$ SDS-PAGE and underwent western blotting. The results of western blot analysis were semi-quantified using ImageJ software (version 1.51u; https://imagej.nih.gov/ij/) supplied by the National Institutes of Health (Bethesda, MD, USA) and relative intensity compared with $\beta$-actin is presented in the bar graphs.

Measurement of reactive oxygen species (ROS). HCT116 p53 $3^{+/+}$ and HCT116 $\mathrm{p}^{-1-}$ cells were cultured in RPMI media with or without $10 \%$ FBS for 24,48 or $72 \mathrm{~h}$. The cells were then collected in $15 \mathrm{ml}$ conical tubes by centrifugation at $\sim 200 \mathrm{x} \mathrm{g}$ for $2 \mathrm{~min}$. Subsequently, $\sim 5 \times 10^{4}$ cells $/ 50 \mu 1$ PBS were added to each well of a 96-well plate and $50 \mu 1200 \mu \mathrm{M}$ 2',7'-dichlorodihydrofluorescein diacetate (DCFH-DA; cat. no. D399; Invitrogen; Thermo Fisher Scientific, Inc.) was added into each well using a multichannel-pipette (PIPETMAN; Gilson Incorporated, Middleton, WI, USA), in order to achieve a final concentration of $100 \mu \mathrm{M}$ DCFH-DA ROS levels were detected by measuring fluorescence at an excitation wavelength of 485 $\mathrm{nm}$ and an emission wavelength of $535 \mathrm{~nm}$ every $5 \mathrm{~min}$ for 30 min with a Gemini XPA microplate reader.

Measurement of mitochondrial membrane potential (MMP). MMP was assessed using a Mito-ID Membrane Potential Cytotoxicity kit (cat. no. ENZ-51019; Enzo Life Sciences, Inc.), according to the manufacturer's protocol. Briefly, HCT116 p53 $3^{+/+}$and HCT116 p53 $3^{-/-}$cells $\left(\sim 2 \times 10^{5}\right.$ cells/well $)$ were cultured in 96-well plates (BD Falcon; BD Biosciences, Franklin Lakes, NJ, USA) in RPMI media with or without $10 \%$ FBS for 48 or $72 \mathrm{~h}$. Subsequently, Mito-ID membrane potential dye loading solution was added to each well and was incubated for $3 \mathrm{~h}$ at room temperature. MMP was assessed by measuring the resulting fluorescence with a Gemini XPA microplate reader, at an excitation wavelength of $480 \mathrm{~nm}$ and an emission wavelength of $590 \mathrm{~nm}$.

Measurement of cellular ATP levels. Cellular ATP levels were measured using the Luminescent ATP Detection Assay kit (cat. no. ab113849; Abcam, Cambridge, MA, USA), according to the manufacturer's protocol. Briefly, HCT116 $\mathrm{p}^{+/+}$and

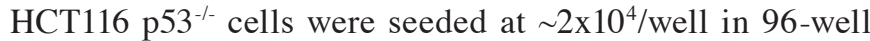
plates for $24 \mathrm{~h}$. Subsequently, cells were incubated in RPMI media with or without $10 \%$ FBS and were cultured for $24 \mathrm{~h}$. Detergent solution $(50 \mu \mathrm{l})$ was then added to each well and the plate was agitated for $5 \mathrm{~min}$ at $600-700 \mathrm{rpm}$ in an orbital shaker, in order to lyse the cells. Subsequently, $50 \mu \mathrm{l}$ reconstituted substrate solution was added and the plate was agitated for a further $5 \mathrm{~min}$. After $10 \mathrm{~min}$ in the dark, cellular ATP levels were measured by detecting luminescence using the GloMax $^{\circledR}$ Discover multimode microplate reader (Promega Corporation, Madison, WI, USA).

Statistical analysis. Data are presented as the means \pm standard deviation from three independent experiments. $\mathrm{S}$ tatistical analysis was performed using Student's t-test to compare two different groups or one-way analysis of variance, followed by Bonferroni's multiple comparisons test, to compare multiple groups. SPSS statistics version 23 was used to analyze data (IBM Corporation, Armonk, NY, USA). $\mathrm{P}<0.05$ was considered to indicate a statistically significant difference.

\section{Results}

Cell proliferation is increased and cell death is reduced in HCT116 $\mathrm{p53} 3^{-/}$human colon cancer cells under nutrient/serum starvation. To explore the effects of $\mathrm{p} 53$ on necroptosis under nutrient/serum starvation, the present study compared cell proliferation and cell death between HCT116 $\mathrm{p} 53^{+/+}$and HCT116 $\mathrm{p}^{-/-}$cells after culturing them in CM or SS for 24 , 48 or $72 \mathrm{~h}$. HCT116 $\mathrm{p} 53^{--}$cells exhibited a higher growth rate

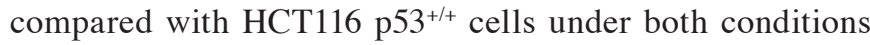
(Fig. 1A). Cell images were also obtained under an optical microscope. Microscope images revealed that, in response to

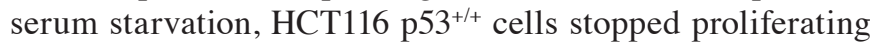
and exhibited the typical morphological alterations of cell death, including detachment from the bottom of the plate and generation of round-shaped, shrunk or swollen cells, whereas 

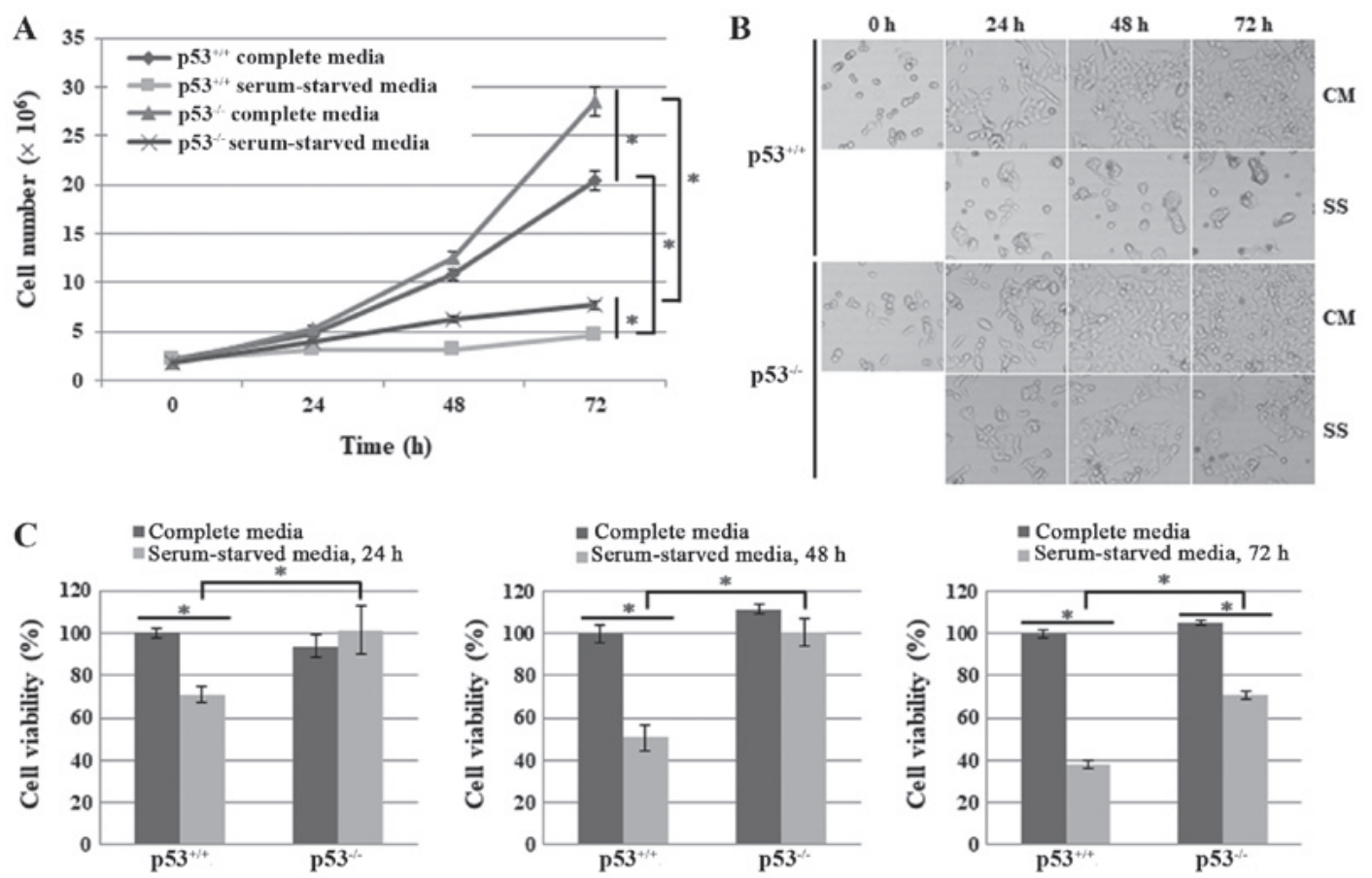

Figure 1. Effects of p53 on the proliferation and viability of HCT116 cells under conditions of serum starvation. (A) HCT116 p53 $3^{+/+}$and HCT116 p53 $3^{-/}$cells were cultured in RPMI-1640 with or without serum for the indicated durations $(0,24,48$ and $72 \mathrm{~h})$. Growth rates were compared by Trypan blue staining following an initial plating density of $\sim 10^{6}$ cells per $100-\mathrm{mm}$ plate; cells were counted for 4 days. Data are presented as the means \pm standard deviation from

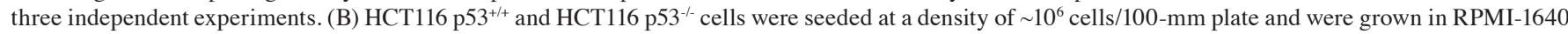
media with or without serum. Morphological images were captured under an optical microscope at x100 magnification. (C) Viable cells were evaluated by measuring the absorbance at $450 \mathrm{~nm}$. Data are presented as the means \pm standard deviation from three independent experiments. ${ }^{*} \mathrm{P}<0.05$. CM, complete media; SS, serum-starved media.

HCT116 $\mathrm{p} 53^{-/}$cells exhibited far fewer morphological alterations, although proliferation was greatly decreased (Fig. 1B). The cell viability assay also revealed a lower level of cell growth and viability in HCT116 $\mathrm{p} 53^{+/+}$cells compared with HCT116 $\mathrm{p} 53^{-/}$cells following serum deprivation for 24 , 48 and $72 \mathrm{~h}$ (Fig. 1C). Taken together, these results suggested that p53 may suppress cell proliferation and enhance cell death under the stress of nutrient/serum starvation.

Necroptosis is reduced in HCT116 p53\% cells in response to nutrient/serum starvation. HCT116 $\mathrm{p} 53^{-/}$cells exhibited reduced cell death under serum deprivation. To investigate whether loss of p53 exerts inhibitory effects on necroptosis, the extracellular levels of necroptosis biomarkers, CypA and HMGB1, were detected using western blotting after HCT116 $\mathrm{p} 53^{+/+}$and HCT116 $\mathrm{p} 53^{-/-}$cells were grown in RPMI media with or without serum for 24,48 and $72 \mathrm{~h}$ (Fig. 2). The export of both proteins into the extracellular media was significantly increased after $48 \mathrm{~h}$ serum starvation in both cell lines, indicating the induction of necroptosis (Fig. 2A and B). However, the extracellular levels were much higher for HCT116 $\mathrm{p} 53^{+/+}$cells than for HCT116 $\mathrm{p} 53^{-/-}$cells after $72 \mathrm{~h}$, thus indicating that necroptosis was suppressed in HCT116 p53 $^{-/}$cells (Fig. 2A and B). In addition, PARP cleavage was increased in HCT116 $\mathrm{p}^{+/ /+}$cells compared with in HCT116 $\mathrm{p}^{-/-}$cells, thus suggesting that the loss of p53 suppressed apoptotic cell death, as well as necroptosis (Fig. 2A and B). The expression levels of $\mathrm{p} 53$ were decreased

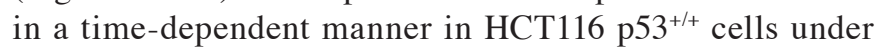
the conditions of serum starvation (Fig. 2A and B).
The induction of necroptosis and apoptosis in HCT116 p53 $3^{+/+}$and HCT116 p53 $^{-/}$cells was examined by confocal microscopy; 7-AAD and Annexin $\mathrm{V}$ staining were used to detect necroptosis and apoptosis, respectively (Fig. 2C and D). In response to serum starvation for $72 \mathrm{~h}$, marked 7-AAD and Annexin V fluorescence was detected in both cell lines, thus indicating that necroptosis and apoptotic cell death pathways were induced; much higher levels of necroptosis and apoptosis were detected in HCT116 p53 $^{+/+}$cells compared with HCT116 p53 $3^{-/}$cells (Fig. 2C and 2D).

Taken together, these results suggested that the absence of p53 in HCT116 cells may suppress necroptosis to a higher degree than in $\mathrm{p} 53^{+/+}$cells under serum starvation.

Effects of p53 on mitochondria-mediated necroptosis under serum starvation. To determine the role of $\mathrm{p} 53$ in necroptosis, it was hypothesized that p53 may induce it by regulating mitochondrial functions, including the production of ROS, maintenance of the MMP, or generation of ATP. These functions are understood to be strongly associated with several types of cell death; very high levels of ROS, and low levels of MMP and ATP, are known to accelerate cell death pathways (30-39). Therefore, the present study detected the cellular levels of ROS and ATP, as well as the MMP, in HCT116 p53 $3^{+/+}$ and HCT116 $\mathrm{p} 53^{-/}$cells under serum starvation.

Cellular ROS levels were detected in HCT116 p53 $3^{+/+}$ and HCT116 $\mathrm{p}^{-/-}$cells cultured in media with or without serum for various durations. The results revealed that there was no significant difference between the cell lines until 48 h (data not shown). However, ROS levels were significantly 
A
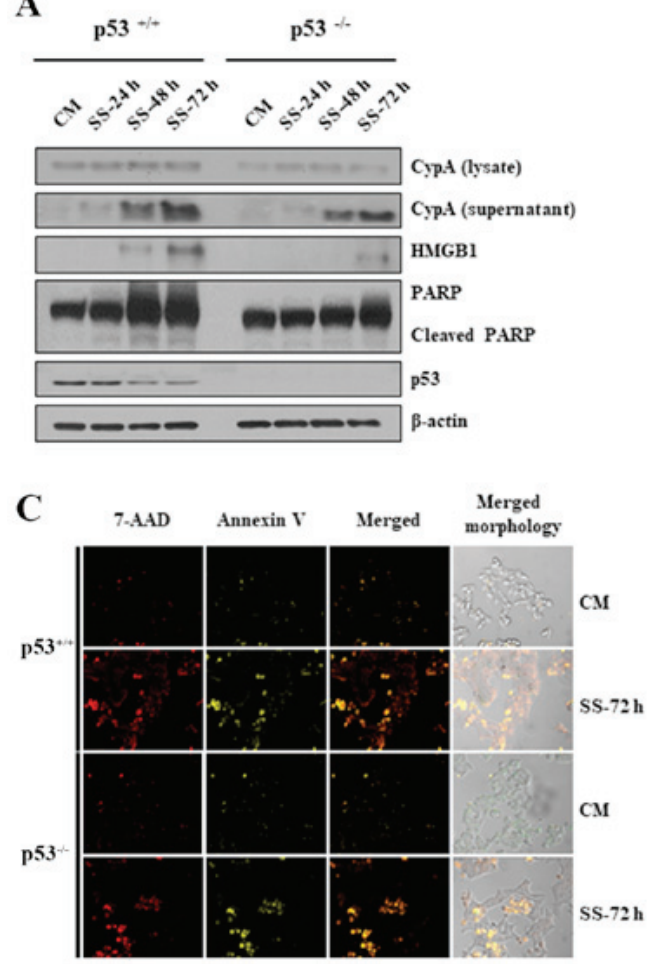
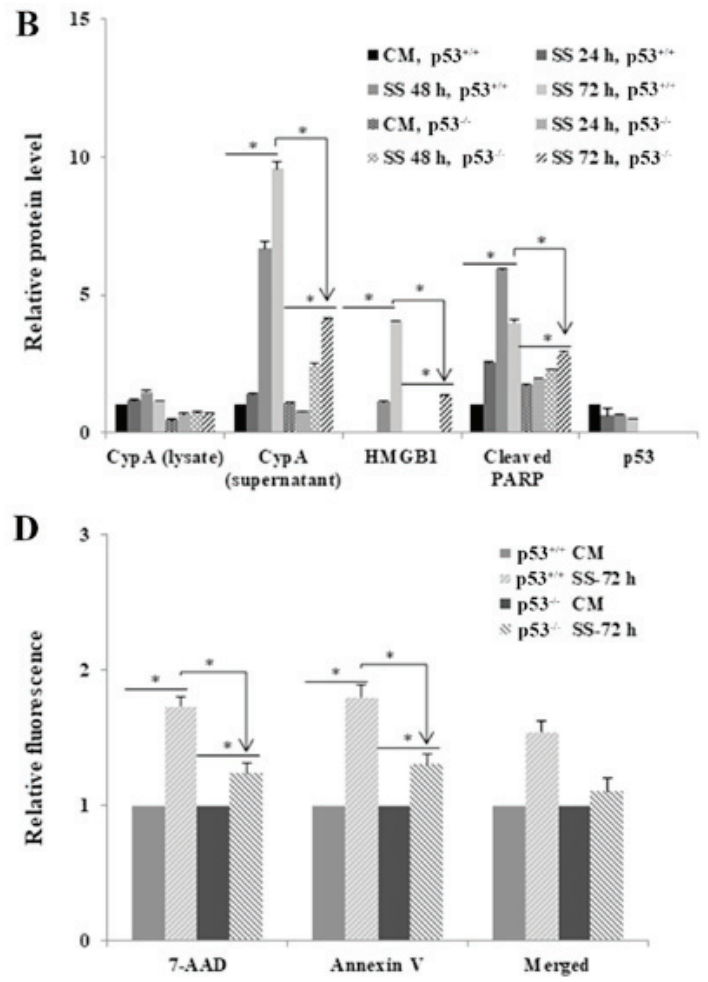

Figure 2. Necroptosis is reduced in HCT116 p53 $3^{-/}$cells under serum starvation. (A) HCT116 p53 $3^{+/+}$and $\mathrm{HCT} 116$ p53 $3^{-/}$cells were grown in CM or SS for 24 , 48 and $72 \mathrm{~h}$. Western blotting was performed to detect representative biomarkers: CypA and HMGB1 for necroptosis, and PARP for apoptosis. $\beta$-actin was used as a loading control. All experiments were performed independently at least three times and representative data are shown. (B) Western blotting was semi-quantified using ImageJ. ${ }^{*} \mathrm{P}<0.05$. (C) Cells $\left(2 \times 10^{5}\right)$ were cultured in CM or SS for $72 \mathrm{~h}$ after seeding in a 35 -mm confocal dish. Cells were observed under a confocal microscope (magnification, x200) after staining with Annexin V-EnzoGold (enhanced Cyanine-3) to detect apoptosis (yellow staining) and (7-AAD) to detect necroptosis (red staining). (D) Results were semi-quantified using ImageJ. * $\mathrm{P}<0.05$. 7-AAD, 7-aminoactinomycin D; CM, complete media; CypA, cyclophilin A; HMGB1, high mobility group box 1; PARP, poly (ADP-ribose) polymerase; SS, serum-starved media.
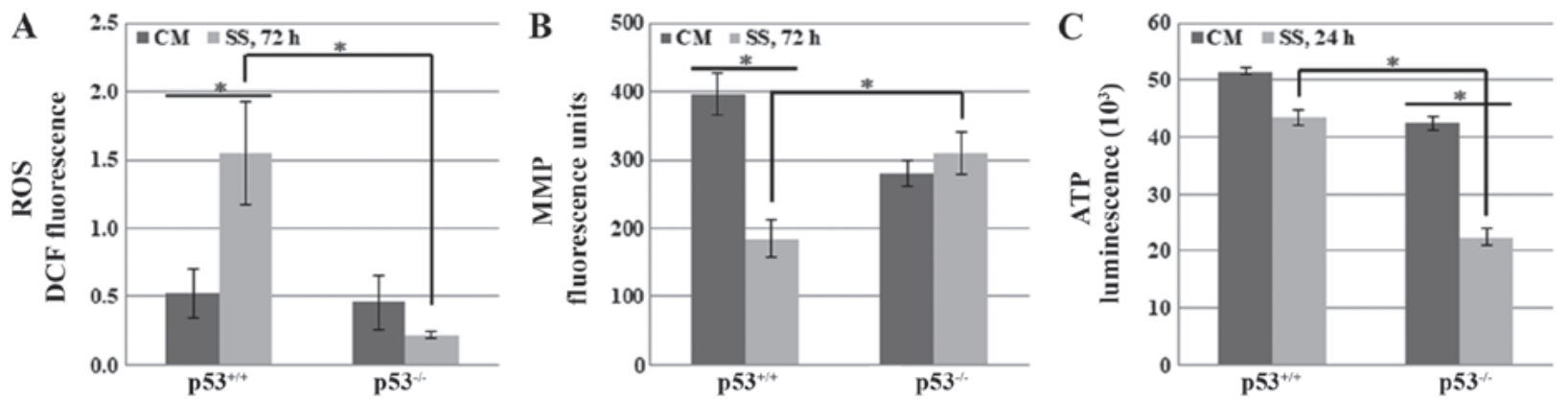

Figure 3. Effects of p53 on cellular levels of ROS and ATP, as well as the MMP, in response to serum starvation. HCT116 p53 $3^{+/+}$and HCT116 p53 ${ }^{-/-}$cells were incubated in media with or without serum for the indicated durations, and (A) cellular levels of ROS, (B) MMP and (C) cellular levels of ATP were measured. Data are presented as the means \pm standard deviation from three independent experiments. ${ }^{*} \mathrm{P}<0.05$. CM, complete media; DCF, dichlorofluorescein; MMP, mitochondrial membrane potential; ROS, reactive oxygen species; SS, serum-starved media.

increased after $72 \mathrm{~h}$ in $\mathrm{HCT} 116 \mathrm{p} 53^{+/+}$cells, whereas they were slightly decreased in HCT116 $553^{-/-}$cells (Fig. 3A). These data suggested that p53-mediated necroptosis, at least in part, may occur by increasing cellular ROS levels under serum starvation.

Another mitochondrial mediator of cell death, MMP, was also compared between HCT116 p53 ${ }^{+/+}$and HCT116 p53 ${ }^{-/}$cells. Cells were grown in SS for 24, 48 and $72 \mathrm{~h}$. MMP was markedly decreased after $72 \mathrm{~h}$ in HCT116 p53 ${ }^{+/+}$cells, whereas no significant difference was observed in HCT116 $\mathrm{p} 53^{-/-}$cells (Fig. 3B). These data indicated that p53 may induce necroptosis by decreasing MMP in response to serum starvation.
Notably, several types of cell death are accompanied by ATP depletion (40-43). Therefore, the effects of $\mathrm{p} 53$ on cellular ATP levels were assessed in response to serum starvation. The results indicated that ATP levels were decreased in both cell lines. However, it was unexpectedly observed that ATP levels were more markedly decreased in HCT $116 \mathrm{p} 53^{-/}$cells, whereas they were only slightly reduced in HCT116 $\mathrm{p} 53^{+/+}$cells after 24 h (Fig. 3C).

Taken together, these findings supported the hypothesis that p53 may accelerate necroptosis, at least partially, by increasing ROS levels and decreasing MMP in HCT116 cells under serum starvation. 

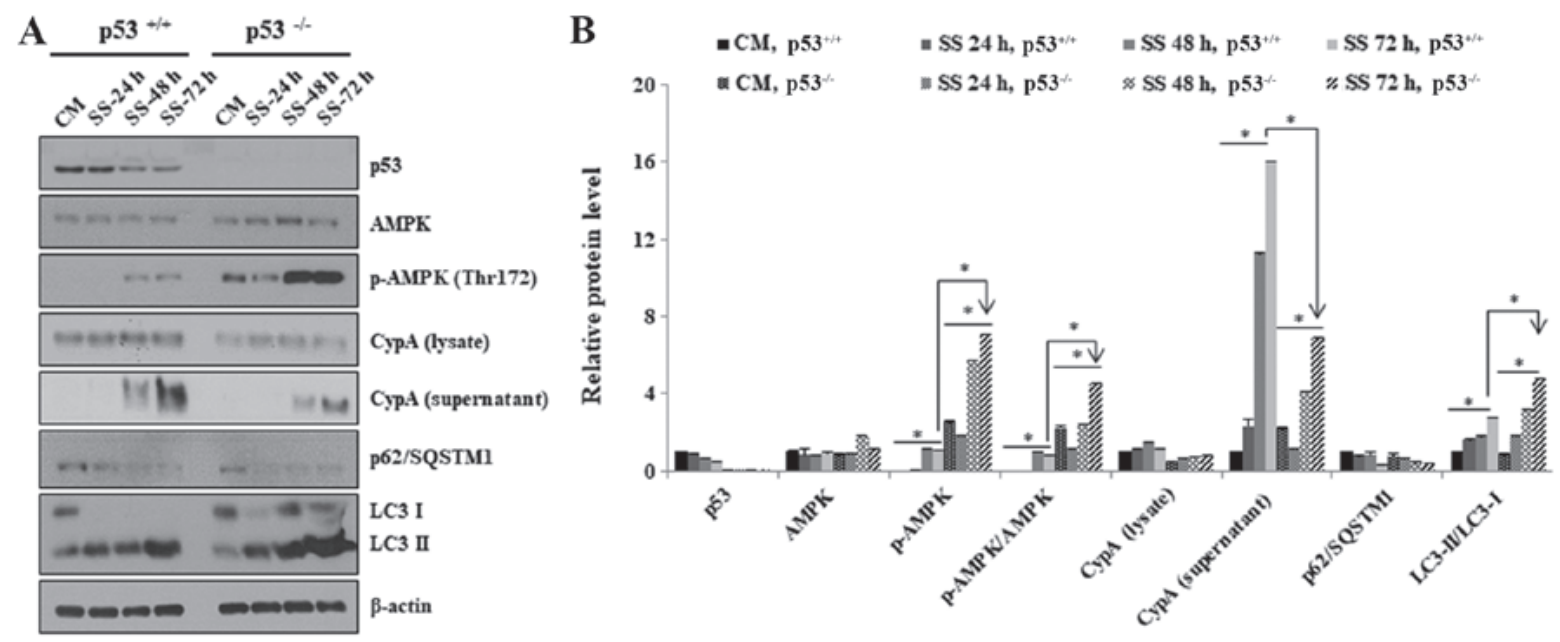

Figure 4. Negative effects of p53 on AMPK activation in response to serum starvation. (A) HCT116 $553^{+/+}$and HCT116 p53 $3^{-/}$cells were grown in CM or SS for 24, 48 and $72 \mathrm{~h}$. Western blotting was used to determine the expression levels of AMPK, p-AMPK (Thr172), CypA, p62/SQSTM1 and LC3. $\beta$-actin was used as a loading control. All experiments were performed independently at least three times and representative data are shown. (B) Western blots were semi-quantified using ImageJ. " $\mathrm{P}<0.05$. The ratio of p-AMPK (Thr172) to total AMPK is shown as p-AMPK/AMPK. AMPK, AMP-activated protein kinase; CM, complete media; CypA, cyclophilin A; LC3, microtubule-associated protein 1A/1B-light chain 3; p, phosphorylated; SQSTM1, sequestome 1; SS, serum-starved media.

AMPK activation is increased in $153^{-/}$cells under serum starvation. It is well known that nutrient starvation (e.g., depletion of glucose, amino acids or serum) leads to decreased intracellular ATP levels and that further extreme depletion may eventually induce cell death. Based on the importance of cellular ATP levels with regards to cell survival, it was expected that ATP levels would be lower in HCT116 p53 ${ }^{+/+}$cells, due to the higher levels of necroptosis. However, the present data revealed that ATP levels were lower in HCT116 p53 ${ }^{--}$cells in both CM and SS (Fig. 3C). In addition, much higher levels of proliferation were detected in HCT116 p53 ${ }^{-/}$cells compared with in HCT116 p53 $3^{+/+}$cells under serum starvation (Fig. 1). Therefore, it was hypothesized that ATP levels may be lower in $\mathrm{p} 53^{-1-}$ cells due to uncontrolled rapid cell proliferation and growth, which may cause much higher consumption of ATP. ATP depletion is the main signal that induces AMPK activation by phosphorylation of Thr172 (44-46). The present study demonstrated that serum starvation markedly increased phosphorylation of AMPK at Thr172 in HCT116 p53-- cells compared with in HCT116 p53 ${ }^{+/+}$cells. Even though there was a slight variation in the expression levels of total AMPK (Fig. 4A and B), the ratio of p-AMPK (Thr172) to total AMPK (p-AMPK/AMPK) indicated the significant increase in levels of AMPK phosphorylation (Fig. 4B). Therefore, it was hypothesized that AMPK activation may be involved in necroptotic cell death in a p53-dependent manner in response to serum depletion.

A well-known function of activated AMPK is the induction of autophagy, as one of the master regulators. Accordingly, autophagy was analyzed by detecting two well-known biomarkers, p62/SQSTM1 and LC3. The results revealed that serum deficiency decreased the expression levels of p62/SQSTM1 and increased the conversion ratio of LC3-I to LC3-II in HCT116 p53 $3^{-/}$and HCT116 p53 ${ }^{+/+}$cells, thus indicating autophagic induction (Fig. 4A and B). However, p62/SQSTM1 protein levels were decreased to a slightly higher level in HCT116 p53 ${ }^{--}$cells after 24 h (Fig. 4A and B).
In addition, the conversion ratio from LC3-I to LC3-II was also greater in HCT116 p53 ${ }^{--}$cells after $48 \mathrm{~h}$ (Fig. 4A and B). These data suggested that AMPK may be activated in HCT116 p53 ${ }^{-/}$cells at a higher level compared with in HCT116 p53 $3^{+/+}$cells.

Taken together, these results indicated that AMPK activation was highly induced in $\mathrm{p} 53^{-/-}$compared with in $\mathrm{p} 53^{+/+}$cells, probably due to reduced ATP levels.

AMPK activation alleviates necroptosis in HCT116 $\mathrm{p5}^{-/-}$cells but not in HCT116 $\mathrm{p5}^{+/+}$cells under serum starvation. To investigate whether activated AMPK is responsible for the inhibition of necroptotic cell death in $\mathrm{p} 53^{-/-}$cells, the effects of AMPK activation on necroptosis were examined using an AMPK inhibitor and AMPK activator.

AMPK activity was suppressed using the potent and selective AMPK inhibitor, DM. HCT116 p53 ${ }^{+/+}$and HCT116

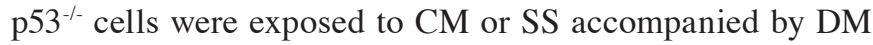
at various doses $(0,5$ and $10 \mu \mathrm{M})$ for $48 \mathrm{~h}$ (Fig. $5 \mathrm{~A}$ and $\mathrm{B}$ ). Phosphorylation of AMPK at residue Thr172 was significantly decreased following treatment with 5 and $10 \mu \mathrm{M}$ DM, thus indicating that AMPK activation was successfully inhibited (Fig. 5A and B). Notably, the export of CypA was markedly increased in HCT116 p53/- cells in response to DM, even in $\mathrm{CM}$ (Fig. 5A and B); in addition, no significant differences were detected in CypA export between HCT116 p53 ${ }^{+/+}$and HCT116 p53 ${ }^{-/}$cells following DM treatment (Fig. 5A and B). These findings strongly suggested that serum starvation-induced AMPK activation effectively suppressed necroptosis in the p53 ${ }^{-/-}$cells.

Secondly, AMPK activation was enhanced by AICAR, which mimics the effects of AMP (21,47-49). HCT116 p53 $3^{+/+}$ and HCT116 p53 $^{-/}$cells were cultured in CM and SS with various concentrations of $\operatorname{AICAR}(75,150$ and $300 \mu \mathrm{M})$ for $48 \mathrm{~h}$ (Fig. 5C and D). The results revealed that phosphorylation of AMPK at residue Thr172 was increased in HCT116 p53 $3^{+/+}$cells following AICAR treatment, thus indicating that AMPK activity was successfully enhanced (Fig. 5C and D). AMPK 


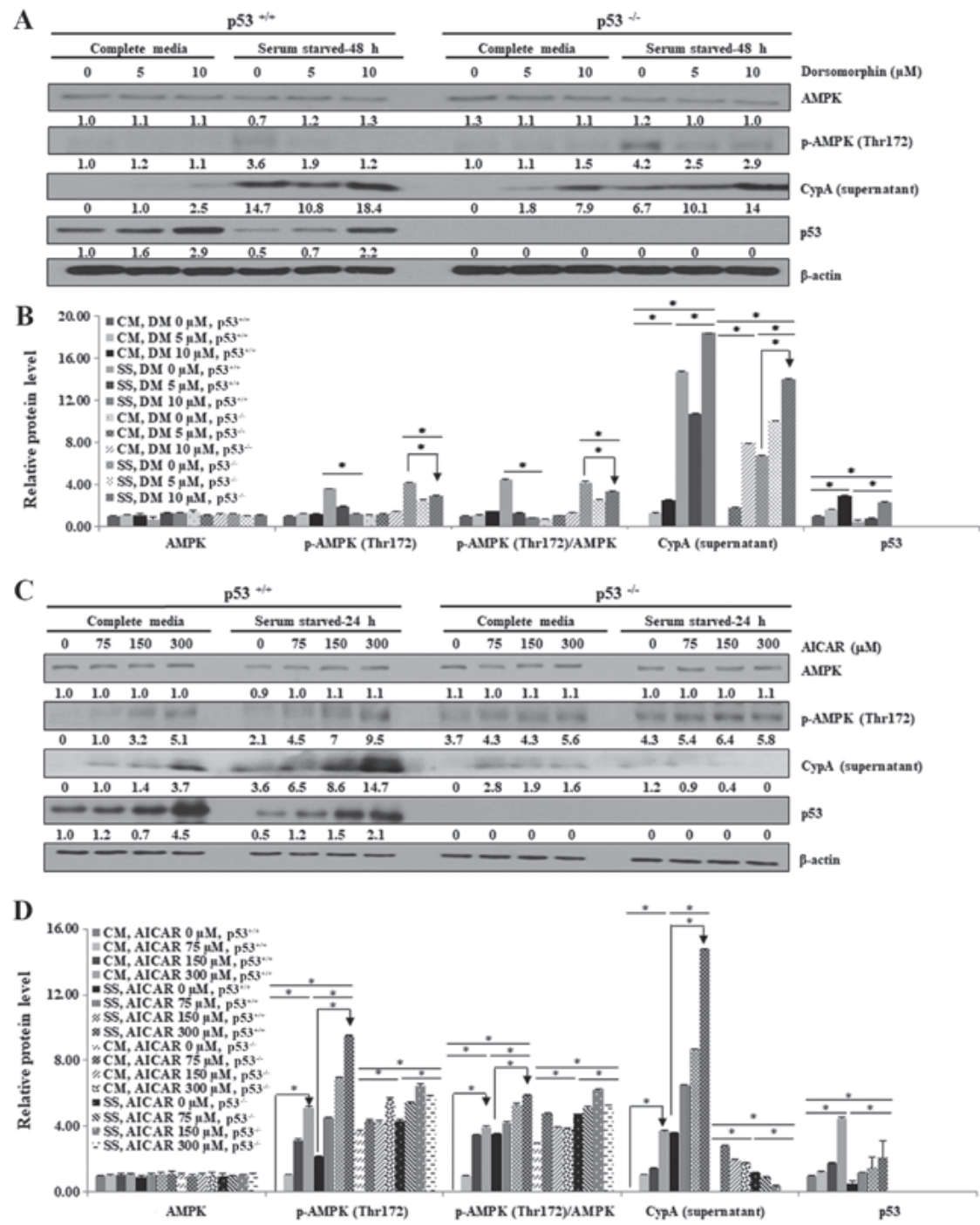

Figure 5. AMPK activation alleviates necroptosis in HCT116 p53/- cells but not in HCT116 p53 $3^{+/+}$cells under serum starvation. HCT116 p53 ${ }^{+/+}$and $\mathrm{HCT} 116$

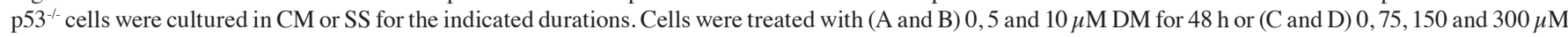
AICAR for $48 \mathrm{~h}$. (A and C) Lysates were obtained and analyzed by western blotting, in order to detect phosphorylation of AMPK on the Thr172 residue, and the expression levels of CypA and p53. $\beta$-actin was used as a loading control. (B and D) Western blotting results were semi-quantified using ImageJ. The experiment was performed independently at least three times and representative data are shown. ${ }^{*} \mathrm{P}<0.05$. Numbers represent relative intensity versus $\beta$-actin. The ratio of p-AMPK (Thr172) to total AMPK is shown as p-AMPK/AMPK. AICAR, 5-aminoimidazole-4-carboxamide ribonucleotide; AMPK, AMP-activated protein kinase; CM, complete media; CypA, cyclophilin A; DM, dorsomorphin dihydrochloride; p, phosphorylated; SS, serum-starved media.

activation was consistently high in HCT116 $\mathrm{p} 53^{-/-}$cells even prior to AICAR treatment. AICAR treatment slightly increased CypA export into the extracellular media in HCT116 $\mathrm{p5}^{+/+}$and HCT116 p53 ${ }^{-/}$cells maintained in CM (Fig. 5C and D). Notably, extracellular CypA levels were not decreased but were markedly increased in HCT116 p53 ${ }^{+/+}$cells, whereas no alteration was detected in HCT116 $\mathrm{p} 53^{-/-}$cells under SS, indicating that enhanced AMPK activation by AICAR can inhibit necroptosis only in HCT116 p53\%- cells (Fig. 5C and D). These findings strongly suggested that AMPK activation may suppress necroptosis only in $\mathrm{p} 53^{-/-}$cells in response to serum starvation.

The present study revealed that inhibition and activation of AMPK promoted necroptosis in HCT116 p53 ${ }^{+/+}$cells under serum starvation, in which p53 protein expression levels were increased (Fig. 5). This may be because abnormal AMPK activity triggered upregulation of p53 and induced necroptosis.

Taken together, these observations suggested that AMPK activation through phosphorylation of Thr172 enhanced inhibition of necroptosis in $\mathrm{p} 53^{-/-}$cells, but not in $\mathrm{p} 53^{+/+}$cells, under nutrient/serum starvation.

AMPK inhibits necroptosis through the suppression of ROS generation in $p 53^{-/-}$cells. To address how AMPK activation

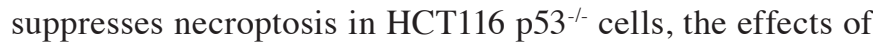
AMPK on cellular levels of ROS and ATP, and on the MMP, were assessed in HCT116 p53 $3^{+/+}$and HCT116 p53/- cells. The results indicated that AMPK inhibition by DM significantly increased ROS generation in HCT116 p53/- cells (Fig. 6A). However, no significant difference was detected in MMP between the HCT116 p53 $3^{+/+}$and HCT116 p53 $3^{-/}$cells, thus indicating that reductions in MMP by AMPK inhibition are independent of p53 (Fig. 6B). Furthermore, DM reduced ATP levels more than SS alone in both cell lines; however, ATP levels were slightly higher in HCT116 p53/- cells

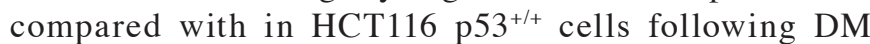
treatment (Fig. 6C). 

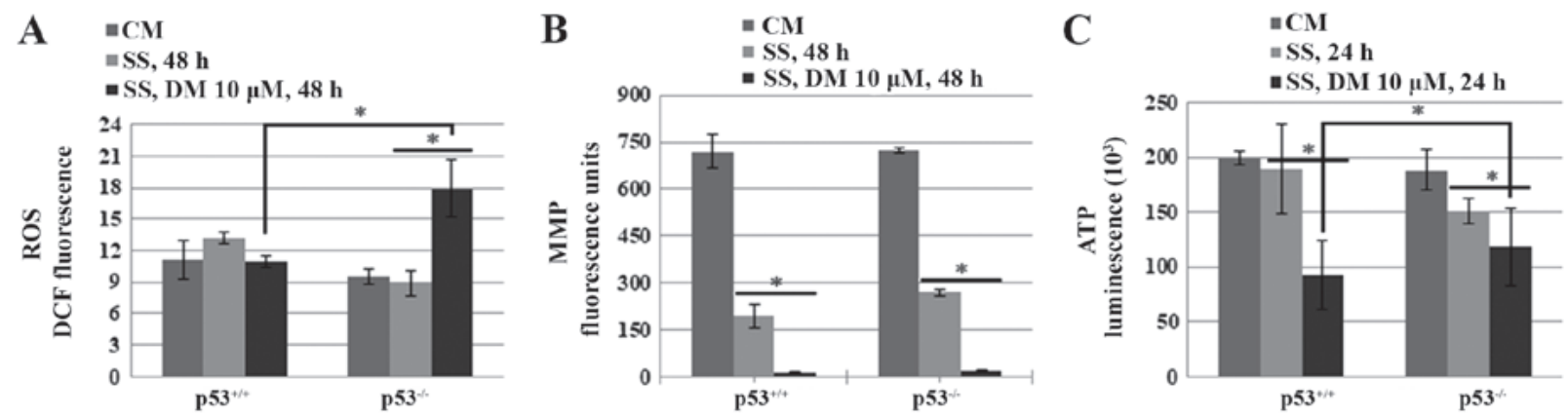

Figure 6. Inhibitory role of AMP-activated protein kinase on ROS generation in HCT116 $\mathrm{p} 53^{-/-}$cells in response to serum starvation. HCT116 $\mathrm{p} 53^{+/+}$and HCT116 p53 cells were cultured in CM or SS for 24 or $48 \mathrm{~h}$. Cells were treated with $10 \mu \mathrm{M}$ DM for the indicated durations, and (A) cellular ROS, (B) MMP and (C) ATP levels were measured. The experiment was performed independently at least three times and representative data are shown. "P $<0.05$. CM, complete media; DCF, dichlorofluorescein; DM, dorsomorphin dihydrochloride; MMP, mitochondrial membrane potential; ROS, reactive oxygen species; SS, serum-starved media.

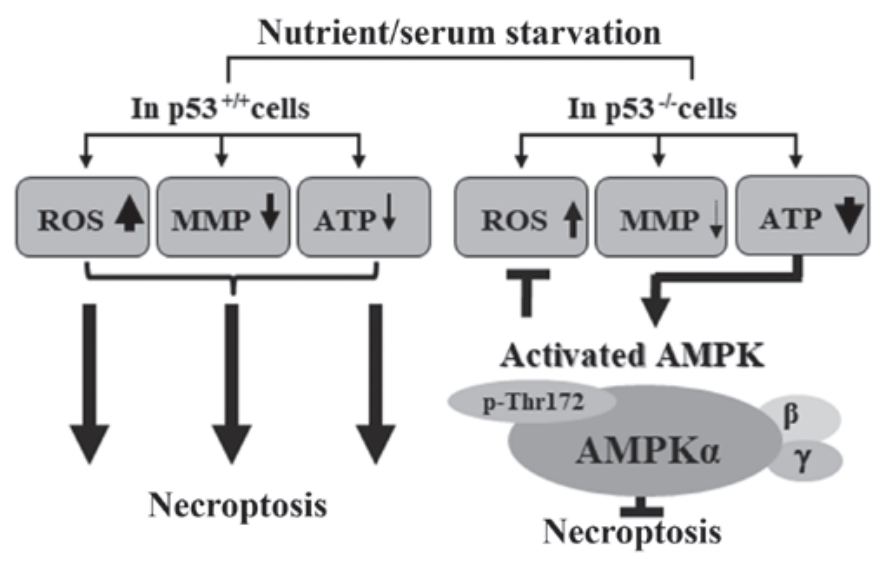

Figure 7. Summary of the inhibitory role of AMPK in necroptosis in p53 ${ }^{-/-}$cells under the stressful condition of nutrient/serum starvation. Nutrient/serum depletion increased ROS generation, and decreased MMP and ATP levels in HCT116 p53 ${ }^{+/+}$cells, resulting in necroptosis. Notably, cellular ATP levels were

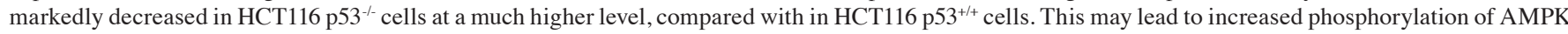
on residue Thr172; ultimately, activation of AMPK inhibited necroptosis by negatively regulating cellular ROS production. AMPK, AMP-activated protein kinase; MMP, mitochondrial membrane potential; ROS, reactive oxygen species.

Taken together, these data indicated that highly activated AMPK may be at least partially responsible for the inhibition of necroptosis via suppression of ROS generation in $\mathrm{p} 53^{-/}$cells.

\section{Discussion}

Escape from cell death, particularly apoptosis, is a serious problem in current cancer research. Therefore, it might be considered an effective therapeutic strategy to trigger several types of cell death at the same time. The present study focused on necroptosis, in addition to apoptosis, with the eventual aim of identifying a novel class of combined targeted therapeutics. The present study revealed that AMPK serves a different role in the regulation of necroptosis in the presence and absence of p53. It was demonstrated that a much lower level of necroptosis was detected in $\mathrm{p} 53^{--}$cells, and serum starvation-induced necroptosis was suppressed by enhancing AMPK activation.

p53 is involved in the regulation of several types of cell death, including apoptosis, CIA, autophagy-mediated cell death, necroptosis, entosis, anoikis, paraptosis, pyroptosis, ferroptosis, mitotic catastrophe and efferocytosis (17). Among these types of cell death, several studies have reported vital roles for p53 in necroptosis. Tu et al demonstrated that p53 can activate necroptosis in response to ROS-induced DNA damage through the activation of the lysosomal cysteine protease, cathepsin Q (50). Furthermore, it has been suggested that 553 accumulates in the mitochondrial matrix, complexes with CypD, and induces necroptosis in response to oxidative stress $(31,32)$. Vaseva et al suggested that p53 causes necroptosis by controlling the opening of the mitochondrial permeability transition pore (32). Montero et al reported that p53 triggers necroptosis by increasing PARP-1 activity, and inducing depletion of NAD and ATP (33). In spite of these studies, the role of p53 in necroptosis remains unclear and more information is required.

There are discordant results regarding the functions of p53 in cell death regulation. Different combinations of master regulators may explain it, each of which has various functions, such as AMPK. The present results revealed that serum starvation-induced AMPK activation suppressed necroptosis in $\mathrm{p} 53^{-/}$cells but not in $\mathrm{p} 53^{+/+}$cells. In contrast to these data, two research groups proposed that AMPK induced necroptosis and apoptosis (51-53). For example, Koo et al suggested that AMPK activation, resulting from impaired mitochondrial oxidative phosphorylation, induces necroptosis in human lung epithelial cells (51). Other research 
groups revealed that AMPK activation induces apoptosis in liver cells by activating signaling pathways, including c-Jun $\mathrm{N}$-terminal kinase and caspase-3 $(52,53)$. However, they did not consider the effects of p53 in their research. It has been reported that the metabolic environmental conditions and pathways that activate AMPK differentially regulate cell proliferation or viability in cancer and normal cells $(19,54)$. Only a few studies have reported on the highly complex interrelationship between p53 and AMPK in cell death. For example, Okoshi et al proposed that AMPK activation induces p53-dependent apoptosis in response to energetic stress (53). Huang et al revealed that AMPK inhibition by $\mathrm{DM}$ induces apoptosis in skin cancer cells via a p53-dependent pathway (55). The same effect of DM was reported in human colorectal cancer cells, with regards to the induction of apoptosis and necroptosis (18). Lee et al also demonstrated that AMPK induces p53 acetylation via phosphorylation and inactivation of sirtuin 1 in liver cancer cells (56). In addition, p53 can regulate autophagy, even though its regulation is controversial, indicating an effect of p53 on AMPK (57-59). However, the exact mechanism underlying the interaction between p53 and AMPK remains elusive.

The present study demonstrated that autophagy was induced at a higher level in HCT116 $\mathrm{p} 53^{-/-}$cells, probably due to enhanced AMPK activation. Numerous studies have reported that autophagy protects cells from cell death under various types of cell death-inducing stress, such as anticancer treatment and severe nutrient starvation (60-62). These data suggested that increased activation of AMPK in HCT116 $\mathrm{p} 53^{--}$cells may induce higher levels of autophagy and eventually suppress other types of cell death in response to serum starvation; however, the association between autophagy and necroptosis requires further study.

RIP1-RIP3-MLKL is known to be a core signaling pathway in necroptosis. The RIP1-RIP3-MLKL-dependent necroptosis machinery may be considered a primary mechanism for suppressing tumorigenesis and cancer progression. Cancer cells may suppress necroptosis by downregulating or inducing functional mutations in RIP1, RIP3 and MLKL. Previous studies indicated that RIP1 expression levels are decreased in only a few cancer cells, whereas RIP3 expression is downregulated in numerous cancer cells (5,63-65). For example, HeLa cervical cancer cells are well known for their resistance to necroptosis, and they express normal levels of RIP1 but no RIP3 expression $(66,67)$. Notably, HCT116 cells have also been reported to lack RIP3 protein $(5,68)$. However,

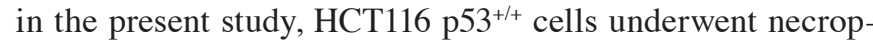
tosis under the stress of serum starvation; therefore, it remains to be determined as to how HCT116 cells undergo necroptosis. Elucidating the mechanism underlying necroptosis will be of great interest.

In conclusion, the present study proposed a plausible model, in which activation of AMPK through phosphorylation of Thr172 may inhibit necroptosis in the absence of p53 in response to serum starvation (Fig. 7). This study proposed that AMPK may be a combined target to efficiently kill cancer cells with defective p53 under low-nutrient conditions. These data provided information regarding a signaling network between p53 and AMPK in necroptosis, which may be provoked in response to serum starvation.

\section{Acknowledgements}

The authors of this study are grateful to Dr. B. Vogelstein (Johns Hopkins University, Baltimore, MD, USA) for generously donating the colorectal carcinoma cell lines, HCT116 p53 and $\mathrm{HCT} 116 \mathrm{p} 53^{--}$, for use in the experiments.

\section{Funding}

The present study was supported by Sookmyung Women's University (2015).

\section{Availability of data and materials}

All data generated or analyzed during this study are included in this published article.

\section{Authors' contributions}

DDTL conducted the majority of the experiments, analyzed data and drafted the manuscript. SJ conceptualized the study, developed the general experimental design, analyzed data and revised the manuscript. NTNQ was involved in the use of ImageJ, statistical analysis and manuscript preparation. ZS assisted in developing the study design and preparing the manuscript. BSL contributed to confocal analysis and preparation of the manuscript. SK, HGL and HJL assisted in experimental preparation, cell culturing and maintenance, and preparation of manuscript. MSL made substantial contributions to conception and experimental design, revised the manuscript and gave final approval of the version to be published. All authors read and approved the manuscript and agree to be accountable for all aspects of this research in ensuring that the accuracy or integrity of any part of the work are appropriately investigated.

\section{Ethics approval and consent to participate}

Not applicable.

\section{Patient consent for publication}

Not applicable.

\section{Competing interests}

The authors declare that they have no competing interests.

\section{References}

1. Pasparakis $\mathrm{M}$ and Vandenabeele P: Necroptosis and its role in inflammation. Nature 517: 311-320, 2015.

2. Vanden Berghe T, Linkermann A, Jouan-Lanhouet S, Walczak H and Vandenabeele P: Regulated necrosis: The expanding network of non-apoptotic cell death pathways. Nat Rev Mol Cell Biol 15: 135-147, 2014.

3. Vandenabeele P, Galluzzi L, Vanden Berghe T and Kroemer G: Molecular mechanisms of necroptosis: An ordered cellular explosion. Nat Rev Mol Cell Biol 11: 700-714, 2010.

4. Teng X, Degterev A, Jagtap P, Xing X, Choi S, Denu R, Yuan J and Cuny GD: Structure-activity relationship study of novel necroptosis inhibitors. Bioorg Med Chem Lett 15: 5039-5044, 2005. 
5. Moriwaki K, Bertin J, Gough PJ, Orlowski GM and Chan FK: Differential roles of RIPK1 and RIPK3 in TNF-induced necroptosis and chemotherapeutic agent-induced cell death. Cell Death Dis 6: e1636, 2015.

6. de Almagro MC and Vucic D: Necroptosis: Pathway diversity and characteristics. Semin Cell Dev Biol 39: 56-62, 2015.

7. Xu YZ, Kanagaratham C, Youssef M and Radzioch D: New Frontiers in Cancer Chemotherapy-Targeting Cell Death Pathways. In: Cell Biology - New Insights. Najman S (ed) IntechOpen, pp93-140, 2016 .

8. Dondelinger Y, Hulpiau P, Saeys Y, Bertrand MJM and Vandenabeele P: An evolutionary perspective on the necroptotic pathway. Trends Cell Biol 26: 721-732, 2016.

9. Belizário J, Vieira-Cordeiro L and Enns S: Necroptotic Cell Death Signaling and Execution Pathway: Lessons from Knockout Mice. Mediators Inflamm 2015: 128076, 2015.

10. Chan FKM, Luz NF and Moriwaki K: Programmed necrosis in the cross talk of cell death and inflammation. Annu Rev Immunol 33: 79-106, 2015

11. Avril T, Vauléon E and Chevet E: Endoplasmic reticulum stress signaling and chemotherapy resistance in solid cancers. Oncogenesis 6: e373, 2017.

12. Palorini R, Votta G, Pirola Y, De Vitto H, De Palma S, Airoldi C, Vasso M, Ricciardiello F, Lombardi PP, Cirulli C, et al: Protein Kinase A Activation Promotes Cancer Cell Resistance to Glucose Starvation and Anoikis. PLoS Genet 12: e1005931, 2016.

13. Izuishi K, Kato K, Ogura T, Kinoshita T and Esumi H: Remarkable tolerance of tumor cells to nutrient deprivation: Possible new biochemical target for cancer therapy. Cancer Res 60: 6201-6207, 2000.

14. Sato K, Tsuchihara K, Fujii S, Sugiyama M, Goya T, Atomi Y, Ueno T, Ochiai A and Esumi H: Autophagy is activated in colorectal cancer cells and contributes to the tolerance to nutrient deprivation. Cancer Res 67: 9677-9684, 2007.

15. Esumi H, Izuishi K, Kato K, Hashimoto K, Kurashima Y, Kishimoto A, Ogura T and Ozawa T: Hypoxia and nitric oxide treatment confer tolerance to glucose starvation in a 5'-AMP-activated protein kinase-dependent manner. J Biol Chem 277: 32791-32798, 2002

16. Kim SM, Nguyen TT, Ravi A, Kubiniok P, Finicle BT, Jayashankar V, Malacrida L, Hou J, Robertson J, Gao D, et al: PTEN deficiency and AMPK activation promote nutrient scavenging and anabolism in prostate cancer cells. Cancer Discov 8 : 866-883, 2018

17. Ranjan A and Iwakuma T: Non-Canonical Cell Death Induced by p53. Int J Mol Sci 17: 2068, 2016.

18. Liu X, Chhipa RR, Nakano I and Dasgupta B: The AMPK inhibitor compound $\mathrm{C}$ is a potent AMPK-independent antiglioma agent. Mol Cancer Ther 13: 596-605, 2014.

19. Hardie DG: AMPK and autophagy get connected. EMBO J 30 634-635, 2011

20. Luo Z, Zang M and Guo W: AMPK as a metabolic tumor suppressor: Control of metabolism and cell growth. Future Oncol 6: 457-470, 2010.

21. Mihaylova MM and Shaw RJ: The AMPK signalling pathway coordinates cell growth, autophagy and metabolism. Nat Cell Biol 13: 1016-1023, 2011

22. Liang J and Mills GB: AMPK: A contextual oncogene or tumor suppressor? Cancer Res 73: 2929-2935, 2013.

23. Faubert B, Boily G, Izreig S, Griss T, Samborska B, Dong Z, Dupuy F, Chambers C, Fuerth BJ, Viollet B, et al: AMPK is a negative regulator of the Warburg effect and suppresses tumor growth in vivo. Cell Metab 17: 113-124, 2013.

24. Hardie DG: AMP-activated protein kinase: An energy sensor that regulates all aspects of cell function. Genes Dev 25: 1895-1908, 2011.

25. Li W, Saud SM, Young MR, Chen G and Hua B: Targeting AMPK for cancer prevention and treatment. Oncotarget 6: 7365-7378, 2015.

26. Jeon SM, Chandel NS and Hay N: AMPK regulates NADPH homeostasis to promote tumour cell survival during energy stress. Nature 485: 661-665, 2012.

27. Kato K, Ogura T, Kishimoto A, Minegishi Y, Nakajima N, Miyazaki M and Esumi H: Critical roles of AMP-activated protein kinase in constitutive tolerance of cancer cells to nutrient deprivation and tumor formation. Oncogene 21: 6082-6090, 2002.

28. Bunz F, Dutriaux A, Lengauer C, Waldman T, Zhou S, Brown JP, Sedivy JM, Kinzler KW and Vogelstein B: Requirement for p53 and p21 to sustain G2 arrest after DNA damage. Science 282: 1497-1501, 1998
29. Christofferson DE and Yuan J: Cyclophilin A release as a biomarker of necrotic cell death. Cell Death Differ 17: 1942-1943, 2010.

30. Lin Y, Choksi S, Shen H-M, Yang Q-F, Hur GM, Kim YS, Tran JH, Nedospasov SA and Liu ZG: Tumor necrosis factor-induced nonapoptotic cell death requires receptor-interacting protein-mediated cellular reactive oxygen species accumulation. J Biol Chem 279: 10822-10828, 2004.

31. Dashzeveg N and Yoshida K: Cell death decision by p53 via control of the mitochondrial membrane. Cancer Lett 367: 108-112, 2015.

32. Vaseva AV, Marchenko ND, Ji K, Tsirka SE, Holzmann S and Moll UM: p53 opens the mitochondrial permeability transition pore to trigger necrosis. Cell 149: 1536-1548, 2012.

33. Montero J, Dutta C, van Bodegom D, Weinstock D and Letai A p53 regulates a non-apoptotic death induced by ROS. Cell Death Differ 20: 1465-1474, 2013.

34. Tsujimoto Y and Shimizu S: Role of the mitochondrial membrane permeability transition in cell death. Apoptosis 12: 835-840, 2007.

35. Eguchi Y, Shimizu S and Tsujimoto Y: Intracellular ATP levels determine cell death fate by apoptosis or necrosis. Cancer Res 57: 1835-1840, 1997

36. Tatsumi T, Shiraishi J, Keira N, Akashi K, Mano A, Yamanaka S, Matoba S, Fushiki S, Fliss $\mathrm{H}$ and Nakagawa M: Intracellular ATP is required for mitochondrial apoptotic pathways in isolated hypoxic rat cardiac myocytes. Cardiovasc Res 59: 428-440, 2003.

37. Liou G-Y and Storz P: Reactive oxygen species in cancer. Free Radic Res 44: 479-496, 2010

38. Redza-Dutordoir M and Averill-Bates DA: Activation of apoptosis signalling pathways by reactive oxygen species. Biochim Biophys Acta 1863: 2977-2992, 2016.

39. Marchi S, Giorgi C, Suski JM, Agnoletto C, Bononi A, Bonora M, De Marchi E, Missiroli S, Patergnani S, Poletti F, et al: Mitochondria-ros crosstalk in the control of cell death and aging. J Signal Transduct 2012: 329635, 2012.

40. Fulda S: The mechanism of necroptosis in normal and cancer cells. Cancer Biol Ther 14: 999-1004, 2013.

41. Kaczmarek A, Vandenabeele P and Krysko DV: Necroptosis: The release of damage-associated molecular patterns and its physiological relevance. Immunity 38: 209-223, 2013.

42. Dasgupta A, Nomura M, Shuck R and Yustein J: Cancer's Achilles' Heel: Apoptosis and Necroptosis to the Rescue. Int J Mol Sci 18: 23, 2016.

43. González-Juarbe N, Gilley RP, Hinojosa CA, Bradley KM, Kamei A, Gao G, Dube PH, Bergman MA and Orihuela CJ: Pore-Forming Toxins Induce Macrophage Necroptosis during Acute Bacterial Pneumonia. PLoS Pathog 11: e1005337, 2015.

44. Steinberg GR and Kemp BE: AMPK in Health and Disease. Physiol Rev 89: 1025-1078, 2009.

45. Oakhill JS, Chen Z-P, Scott JW, Steel R, Castelli LA, Ling N, Macaulay SL and Kemp BE: $\beta$-Subunit myristoylation is the gatekeeper for initiating metabolic stress sensing by AMP-activated protein kinase (AMPK). Proc Natl Acad Sci USA 107: 19237-19241, 2010

46. Yung MMH, Ngan HYS and Chan DW: Targeting AMPK signaling in combating ovarian cancers: Opportunities and challenges. Acta Biochim Biophys Sin (Shanghai) 48: 301-317, 2016.

47. Wang W, Yang X, López de Silanes I, Carling D and Gorospe M: Increased AMP:ATP ratio and AMP-activated protein kinase activity during cellular senescence linked to reduced HuR function. J Biol Chem 278: 27016-27023, 2003.

48. Grahame Hardie D: Regulation of AMP-activated protein kinase by natural and synthetic activators. Acta Pharm Sin B 6: 1-19, 2016

49. Smith AC, Bruce CR and Dyck DJ: AMP kinase activation with AICAR simultaneously increases fatty acid and glucose oxidation in resting rat soleus muscle. J Physiol 565: 537-546, 2005.

50. Tu HC, Ren D, Wang GX, Chen DY, Westergard TD, Kim H, Sasagawa S, Hsieh JJD and Cheng EHY: The p53-cathepsin axis cooperates with ROS to activate programmed necrotic death upon DNA damage. Proc Natl Acad Sci USA 106: 1093-1098, 2009.

51. Koo MJ, Rooney KT, Choi ME, Ryter SW, Choi AMK and Moon JS: Impaired oxidative phosphorylation regulates necroptosis in human lung epithelial cells. Biochem Biophys Res Commun 464: 875-880, 2015

52. Meisse D, Van de Casteele M, Beauloye C, Hainault I, Kefas BA, Rider MH, Foufelle F and Hue L: Sustained activation of AMP-activated protein kinase induces c-Jun N-terminal kinase activation and apoptosis in liver cells. FEBS Lett 526: 38-42, 2002 . 
53. Okoshi R, Ozaki T, Yamamoto H, Ando K, Koida N, Ono S, Koda T, Kamijo T, Nakagawara A and Kizaki H: Activation of AMP-activated protein kinase induces p53-dependent apoptotic cell death in response to energetic stress. J Biol Chem 283: 3979-3987, 2008.

54. Ferretti AC, Tonucci FM, Hidalgo F, Almada E, Larocca MC and Favre C: AMPK and PKA interaction in the regulation of survival of liver cancer cells subjected to glucose starvation. Oncotarget 7: 17815-17828, 2016.

55. Huang SW, Wu CY, Wang YT, Kao JK, Lin CC, Chang CC, $\mathrm{Mu}$ SW, Chen YY, Chiu HW, Chang CH, et al: p53 modulates the AMPK inhibitor compound $\mathrm{C}$ induced apoptosis in human skin cancer cells. Toxicol Appl Pharmacol 267: 113-124, 2013.

56. Lee CW, Wong LL, Tse EY, Liu HF, Leong VY, Lee JM, Hardie DG, Ng IO and Ching YP: AMPK promotes p53 acetylation via phosphorylation and inactivation of SIRT1 in liver cancer cells. Cancer Res 72: 4394-404, 2012.

57. Maiuri MC, Galluzzi L, Morselli E, Kepp O, Malik SA and Kroemer G: Autophagy regulation by p53. Curr Opin Cell Biol 22: 181-185, 2010.

58. Scherz-Shouval R, Weidberg H, Gonen C, Wilder S, Elazar Z and Oren M: p53-dependent regulation of autophagy protein LC3 supports cancer cell survival under prolonged starvation. Proc Natl Acad Sci USA 107: 18511-18516, 2010.

59. Tasdemir E, Chiara Maiuri M, Morselli E, Criollo A, D'Amelio M, Djavaheri-Mergny M, Cecconi F, Tavernarakis N and Kroemer G: A dual role of p53 in the control of autophagy. Autophagy 4: 810-814, 2008.

60. Fitzwalter BE and Thorburn A: Recent insights into cell death and autophagy. FEBS J 282: 4279-4288, 2015.
61. Boya P, González-Polo R-A, Casares N, Perfettini J-L, Dessen P, Larochette N, Métivier D, Meley D, Souquere S, Yoshimori T, et al: Inhibition of macroautophagy triggers apoptosis. Mol Cell Biol 25: 1025-1040, 2005.

62. Nikoletopoulou V, Markaki M, Palikaras K and Tavernarakis N: Crosstalk between apoptosis, necrosis and autophagy. Biochim Biophys Acta 1833: 3448-3459, 2013.

63. Nugues AL, El Bouazzati H, Hétuin D, Berthon C, Loyens A, Bertrand E, Jouy N, Idziorek T and Quesnel B: RIP3 is downregulated in human myeloid leukemia cells and modulates apoptosis and caspase-mediated p65/RelA cleavage. Cell Death Dis 5: e1384, 2014.

64. Koo G-B, Morgan MJ, Lee D-G, Kim W-J, Yoon J-H, Koo JS, Kim SI, Kim SJ, Son MK, Hong SS, et al: Methylation-dependent loss of RIP3 expression in cancer represses programmed necrosis in response to chemotherapeutics. Cell Res 25: 707-725, 2015.

65. Yang C, Li J, Yu L, Zhang Z, Xu F, Jiang L, Zhou X and He S: Regulation of RIP3 by the transcription factor Sp1 and the epigenetic regulator UHRF1 modulates cancer cell necroptosis. Cell Death Dis 8: e3084, 2017.

66. Su Z, Yang Z, Xie L, DeWitt JP and Chen Y: Cancer therapy in the necroptosis era. Cell Death Differ 23: 748-756, 2016.

67. Wang Z, Jiang H, Chen S, Du F and Wang X: The mitochondrial phosphatase PGAM5 functions at the convergence point of multiple necrotic death pathways. Cell 148: 228-243, 2012.

68. Brown MF, Leibowitz BJ, Chen D, He K, Zou F, Sobol RW, Beer-Stolz D, Zhang L and Yu J: Loss of caspase-3 sensitizes colon cancer cells to genotoxic stress via RIP1-dependent necrosis. Cell Death Dis 6: e1729, 2015. 